\title{
Atmospheric Cold Plasma Inactivation of Escherichia Coli, Salmonella Enterica Serovar Typhimurium and Listeria Monocytogenes Inoculated on Fresh Produce
}

\author{
Dana Ziuzina \\ Technological University Dublin, dana.ziuzina@tudublin.ie \\ Sonal Patil \\ Technological University Dublin, sonalpatil81@gmail.com \\ Patrick Cullen \\ Technological University Dublin, pj.cullen@tudublin.ie
}

See next page for additional authors

Follow this and additional works at: https://arrow.tudublin.ie/schfsehart

Part of the Food Microbiology Commons, and the Food Processing Commons

\section{Recommended Citation}

Ziuzina, D. et al. (2014). Atmospheric Cold Plasma inactivation of Escherichia coli, Salmonella enterica serovar Typhimurium and Listeria monocytogenes inoculated on fresh produce. Food Microbiology, 42, pp.109-116 DOI: 10.1016/j.fm.2014.02.007

This Article is brought to you for free and open access by the School of Food Science and Environmental Health at ARROW@TU Dublin. It has been accepted for inclusion in Articles by an authorized administrator of ARROW@TU Dublin. For more information, please contact arrow.admin@tudublin.ie, aisling.coyne@tudublin.ie, gerard.connolly@tudublin.ie.

Funder: The research leading to these results has received funding from the European Community

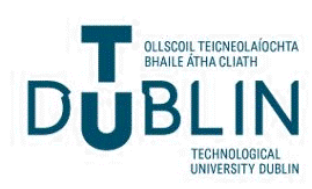




\section{Authors}

Dana Ziuzina, Sonal Patil, Patrick Cullen, Kevin Keener, and Paula Bourke 


\section{Accepted Manuscript}

Atmospheric Cold Plasma inactivation of Escherichia coli, Salmonella enterica serovar Typhimurium and Listeria monocytogenes inoculated on fresh produce

D. Ziuzina, S. Patil, P.J. Cullen, K.M. Keener, P. Bourke

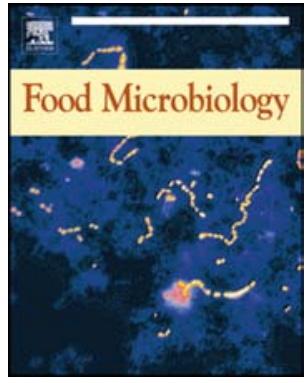

PII:

S0740-0020(14)00032-X

DOI:

10.1016/j.fm.2014.02.007

Reference: $\quad$ YFMIC 2105

To appear in: Food Microbiology

Received Date: 24 June 2013

Revised Date: 13 January 2014

Accepted Date: 11 February 2014

Please cite this article as: Ziuzina, D., Patil, S., Cullen, P.J., Keener, K.M., Bourke, P., Atmospheric Cold Plasma inactivation of Escherichia coli, Salmonella enterica serovar Typhimurium and Listeria monocytogenes inoculated on fresh produce, Food Microbiology (2014), doi: 10.1016/j.fm.2014.02.007.

This is a PDF file of an unedited manuscript that has been accepted for publication. As a service to our customers we are providing this early version of the manuscript. The manuscript will undergo copyediting, typesetting, and review of the resulting proof before it is published in its final form. Please note that during the production process errors may be discovered which could affect the content, and all legal disclaimers that apply to the journal pertain. 


\section{Atmospheric Cold Plasma inactivation of Escherichia coli, Salmonella enterica serovar}

2 Typhimurium and Listeria monocytogenes inoculated on fresh produce

3 D. Ziuzina ${ }^{1}$, S. Patil $1^{1}$, P.J. Cullen ${ }^{1.2}$, K.M. Keener ${ }^{3}$ and P. Bourke ${ }^{1}$

4 1. School of Food Science and Environmental Health, Dublin Institute of Technology,

5 Dublin, Ireland

6 2. School of Chemical Engineering, University of New South Wales, Sydney, Australia.

7 3. Purdue University, Nelson Hall of Food Science, West Lafayette, IN, USA

\section{Corresponding Author:}

9 Paula Bourke, School of Food Science and Environmental Health, Dublin Institute of

10 Technology, Cathal Brugha Street, Dublin 1, Ireland.

11 E-mail: paula.bourke@dit.ie

\section{Abstract}

13 Atmospheric cold plasma (ACP) represents a potential alternative to traditional methods for non-thermal decontamination of foods. In this study, the antimicrobial efficacy of a novel dielectric barrier discharge ACP device against Escherichia coli, Salmonella enterica Typhimurium and Listeria monocytogenes inoculated on cherry tomatoes and strawberries, was examined. Bacteria were spot inoculated on the produce surface, air dried and sealed inside a rigid polypropylene container. Samples were indirectly exposed (i.e. placed outside plasma discharge) to a high voltage $\left(70 \mathrm{kV}_{\mathrm{RMS}}\right)$ air $\mathrm{ACP}$ and subsequently stored at room temperature for $24 \mathrm{~h}$. ACP treatment for 10, 60 and 120 s resulted in reduction of Salmonella, E. coli and L. monocytogenes populations on tomato to undetectable levels from initial populations of 3.1, 6.3, and $6.7 \log _{10} \mathrm{CFU} /$ sample, respectively. However, an extended ACP treatment time was necessary to reduce bacterial populations attached on the more complex 
surface of strawberries. Treatment time for 300 s resulted in reduction of E. coli, Salmonella and L. monocytogenes populations by $3.5,3.8$ and $4.2 \log _{10} \mathrm{CFU} / \mathrm{sample}$, respectively, and also effectively reduced the background microflora of tomatoes.

27 Highlights:

A key advantage of this in-package non-thermal decontamination approach is the possibility to eliminate of post-processing contamination of the produce, thus increasing microbiological food safety and extension of produce shelf life. Inactivation was dependent on fresh produce surface features.

Key words: Atmospheric cold plasma, decontamination efficacy, pathogenic bacteria, fresh produce, ozone.

\section{Introduction}

The benefits associated with consumption of fresh produce maintain a high consumer demand for a wide range of pre-packed ready to use products. Nevertheless, fresh produce may contribute to the transmission of bacterial, parasitic and viral pathogens (Abadias et al. 2008). In recent years, foodborne human illnesses resulting from contaminated fresh produce have been widely reported globally. Most reporting countries identified Escherichia coli O157:H7, Listeria monocytogenes and Salmonella spp. as the target pathogens capable of causing severe human infection and deaths (Rangel et al. 2005; Raybaudi-Massilia et al. 2009; Olaimat and Holley 2012; CDC, 2012). A wide range of fresh fruit and vegetable products have been implicated in foodborne infections, such as lettuce, sprouted seed, melon, tomatoes, radish, pepper, basil and other mixed salads (Fernandez et al. 2013; Olaimat and Holley 2012). Pathogens, such as E. coli O157:H7 and Salmonella may reside in protected sites on surface of the fresh produce and be able to survive for long periods of time beyond the expected shelf-life (Olaimat and Holley 2012). Flessa et al. (2005) reported that $L$. monocytogenes is capable of survival on the surface of fresh intact or cut strawberries 
throughout the shelf life of the fruit and can survive on frozen strawberries for periods of 4 weeks. A health hazard to the consumers may also arise due to the possible presence of microbial toxins as a consequence of produce contamination with spoilage bacteria (IssaZacharia et al. 2010).

Raw fruits and vegetables can become contaminated while growing or during harvesting, postharvest processing, storage or distribution (Cevallos-Cevallos et al. 2012). How bacteria attach and the strength of attachment has not been well understood, but once attached to the surface of fresh produce it is difficult to remove the pathogens by washing (Berger et al. 2010; Warning and Datta 2013). Conventional postharvest washing and sanitising treatments are not highly effective for produce, often resulting in less than $2 \log$ unit reductions of pathogens (Niemira 2012). Moreover, some low $\mathrm{pH}$ based preservation techniques may contribute to the bacterial adaption to acidic environment and subsequently increase their acid resistance (Roberts and Wiedmann 2005). Disinfection can become less effective when microorganisms are attached to produce surface include biofilm formation, concentration reduction of sanitizer near produce surface and accessibility of sanitizer to cells attached to rough surfaces (Wang et al. 2012). Pathogens can also attach to surface through interaction with epiphytic microflora and may be further protected by internalising which itself dependant on many produces phyllosphere characteristics (Erickson 2012).

Non-thermal antimicrobial treatments of fruits, vegetables and other food produce have been the subject of much research. Atmospheric cold plasma (ACP) technology is a relatively new approach aiming to improve microbiological safety in conjunction with maintenance of sensory attributes of the treated foods. A key process advantage is the minimal water usage. However, apart from issues associated with water mediated decontamination, it is likely that many of the features associated with minimal processing and phyllosphere of produce that impact on traditional washing decontamination, may also interact with the optimum 
application of ACP. The antimicrobial efficacy and design of ACP systems including producer gas composition, electrode configuration as well as the type of bacteria and substrate varies widely among research studies (Fernandez et al. 2013, Niemira 2012; Noriega et al. 2011; Niemira and Sites 2008). The use of indirect plasma in conjunction with utilisation of closed chambers for decontamination of meat produce have been highlighted in recent studies conducted by Rod et al. (2012) and Frohling et al. (2012b). Our previous study also demonstrated the antimicrobial efficiency of indirect ACP exposure, where E. coli in a sealed package was readily inactivated within seconds (Ziuzina et al. 2013). However, there are limited numbers of reports based on in-package plasma decontamination of fresh fruits and vegetables (Fan et al. 2012; Klockow and Keener 2009). Therefore, the objective of this study was to evaluate the efficacy of indirect ACP generated inside a sealed package against E. coli, Salmonella and L. monocytogenes inoculated on cherry tomatoes and strawberries and to evaluate its potential to reduce background microflora present on cherry tomatoes and strawberries in order to increase the produce shelf life.

\section{Materials and methods}

\subsection{Bacterial strains and inocula preparation}

Three bacterial strains were used in this study. Escherichia coli NCTC 12900 was obtained from National Collection of type cultures of the Health Protection Agency (HPA, UK), Salmonella enterica Typhimurium ATCC 14028 and Listeria monocytogenes NCTC 11994 were obtained from the microbiology stock culture of the School of Food Science and Environmental Health of the Dublin Institute of Technology. Stock cultures were maintained at $-70^{\circ} \mathrm{C}$ in the form of protective beads (Technical Services Consultants Ltd, UK). One protective bead of each culture was streaked onto separate tryptic soy agar (TSA, ScharlauChemie, Spain), incubated at $37^{\circ} \mathrm{C}$ for $24 \mathrm{~h}$ and further maintained at $4^{\circ} \mathrm{C}$. A single isolated colony of each culture was inoculated in tryptic soy broth without glucose (TSB-G, 
99 ScharlauChemie, Spain) and incubated at $37^{\circ} \mathrm{C}$ for $18 \mathrm{~h}$. The cells were harvested by centrifugation at 10,000 rpm for $10 \mathrm{~min}$, washed twice in sterile phosphate buffered solution (PBS, Oxoid LTD, UK) and finally resuspended in PBS, resulting in concentration of 8-9 $\log _{10} \mathrm{CFU} / \mathrm{ml}$, which were further used as the working inoculum. The concentration of inoculum was confirmed by plating appropriate dilutions on TSA, followed by incubation at $37^{\circ} \mathrm{C}$ for $24 \mathrm{~h}$ for E. coli and Salmonella and $48 \mathrm{~h}$ for L. monocytogenes.

\subsection{Preparation of produce}

Whole fresh cherry tomatoes and strawberries (Class 1, Origin: Spain) were purchased from the local supermarket and stored at $4{ }^{\circ} \mathrm{C}$ until use. The tomatoes were $2 \pm 0.5 \mathrm{~cm}$ in diameter and 5-15 g in weight. Strawberries weight was approximately $10-20 \mathrm{~g}$. The same produce cultivar was used for each experiment. Cherry tomatoes were sterilized with $70 \%$ of ethanol (Klerwipe 70/30, Shield Medicare LTD, Farnham, UK) in order to reduce the background microbial load before surface inoculation of respective bacterial strain. Sterilized samples were then washed with sterile deionized water to remove any remaining ethanol residue and allowed to dry in the laminar flow safety cabinet at $23^{\circ} \mathrm{C}$ for $1 \mathrm{~h}$ prior to inoculation (Mattson et al. 2011). In order to assess ACP treatment efficacy for reduction of the background microflora, unsterilized tomatoes were also used.

\subsection{Fresh produce inoculation procedure}

117 For inoculation, tomatoes and strawberries were placed with the blossom end down on sterile 118 petri dishes. The samples were spot-inoculated with bacteria applying either $50 \mu 1$ or $100 \mu 1$ 119 of a culture on the tomato or strawberry surface, respectively (Das et al. 2006; Mahmoud et al. 2007). The droplets were deposited in several different locations, ensuring that the inoculum did not flow to the side of the samples. Inoculated samples were dried for $1 \mathrm{~h}$ in laminar flow safety cabinet to allow the attachment of bacteria on the surface of produce prior to the ACP treatment. 
124

125

126

127

\subsection{Experimental design}

The ACP system utilised was a dielectric barrier discharge system previously described in Ziuzina et al. (2013), with a maximum high voltage output of $120 \mathrm{kV}$ at $50 \mathrm{~Hz}$. The distance between the two $15 \mathrm{~cm}$ diameter aluminium disk electrodes was $40 \mathrm{~mm}$ which was equal to the height of the polypropylene container $(310 \times 230 \times 40 \mathrm{~mm})$ utilised as both a sample holder and as a dielectric barrier.

Inoculated samples (four of either tomatoes or strawberries) were aseptically transferred on one of the corner of the container so as to expose the samples to indirect ACP discharge (Fig.1). The distance between the samples and centre of the electrodes was within the range from $140 \mathrm{~mm}$ to $160 \mathrm{~mm}$. In order to evaluate ACP treatment efficacy against background microflora, uninoculated samples were used. After product loading, each container was sealed within a high barrier polypropylene film (Cryovac, B2630, USA) and placed between the aluminum electrodes of the transformer. The inoculated and uninoculated samples were treated with $70 \mathrm{kV}_{\mathrm{RMS}}$ for $30 \mathrm{~s}-300 \mathrm{~s}$ in air and at atmospheric pressure. All samples were subjected to a post-treatment storage time of $24 \mathrm{~h}$ at room temperature. In order to evaluate any possible effect of storage on the bacterial growth, inoculated control samples were stored for $24 \mathrm{~h}$ under similar conditions. All experiments were performed in duplicate and replicated three times to ensure reproducibility of the experimental data and are reported as $\log _{10}$ CFU/sample.

\subsection{Microbiological analysis}

For microbiological analysis, inoculated untreated control samples (to estimate initial attached bacterial population), inoculated untreated samples stored for $24 \mathrm{~h}$ (to assess the effect of storage on microbial growth), uninoculated untreated control samples (to determine initial background microflora), and either inoculated or uninoculated ACP treated samples were analyzed. The samples were aseptically transferred into separate sterile stomacher bags 
(BA6041, Seward LTD, UK) with $10 \mathrm{ml}$ of sterile MRD and hand rubbed for 2-3 min. The resulting suspension was serially diluted in MRD. The surviving E. coli, Salmonella and $L$. monocytogenes populations were determined by agar overlay method (Mahmoud 2010). Briefly, aliquots of an appropriate dilution were surface plated on TSA, incubated for 2-4 h, and overlayed with the appropriate selective media: Sorbitol MacConkey agar (SMAC, ScharlauChemie, Spain) supplemented with Cefixime-Tellurite (CT, Oxoid LTD, England) for E. coli, Xylose Lysine Deoxycholate agar (XLD, ScharlauChemie, Spain) for Salmonella, and polymyxin-acriflavine-LiCl-ceftazidime-aesculin-mannitol (PALCAM, ScharlauChemie, Spain) supplemented with PALCAM Listeria Selective Supplement (Oxoid LTD, England) for L. monocytogenes. Plates were then incubated for $24-48 \mathrm{~h}$ at $37^{\circ} \mathrm{C}$.

Surviving background microflora of the uninoculated samples was evaluated using nonselective media TSA for estimation of aerobic mesophilic bacteria and Potato Dextrose agar (PDA, ScharlauChemie, Spain) for estimation of yeasts and moulds, with further incubation of agar plates at $37^{\circ} \mathrm{C}$ and $25^{\circ} \mathrm{C}$, for $48 \mathrm{~h}$ and 5 days, respectively. The limit of detection for bacterial recovery on food samples was $1.0 \log _{10} \mathrm{CFU} /$ sample.

\subsection{Ozone measurements}

Ozone concentration inside the sealed package was measured using Gastec ozone detector tubes (Product \#18M, Gastec Corporation, Japan). Measurements were taken immediately after plasma treatment and after $24 \mathrm{~h}$ of post treatment storage.

\subsection{Scanning Electron Microscopy (SEM)}

171 Attachment of different bacteria, namely E. coli and L. monocytogenes, attached on tomato and strawberry samples was observed using SEM. Inoculated strawberry samples were prepared as described by Gratao et al. (2008) with minor modifications. Briefly, the samples 
were spot inoculated with either bacterium and dried under laminar flow at $23^{\circ} \mathrm{C}$. The tissue from the inoculated sites of the fruit was excised forming $1 \mathrm{~cm}$ in diameter and $1 \mathrm{~mm}$ of thickness pieces. The cells were fixed in ice-cold $2.5 \%$ glutaraldehyde in $0.05 \mathrm{M}$ sodium cacodylate buffer ( $\mathrm{pH} 7.4$ ) (SCB) for $2 \mathrm{~h}$. The cells were washed with the same buffer three times and fixed in $1 \%$ osmium tetroxide for $2 \mathrm{~h}$ at $4^{\circ} \mathrm{C}$. After $2 \mathrm{~h}$ of fixation, bacterial cells were washed with SCB followed by three washes with distilled water. The samples were dehydrated using increasing concentrations of ethanol $(30 \%, 50 \%, 70 \%, 80 \%, 95 \%$, and 99.5\%) and freeze dried (Labconco, FreeZone 6; Mason Technology, Dublin, Ireland). In order to prevent surface charging by the electron beam, the samples were sputter-coated with gold particles using Emitech K575X Sputter Coating Unit resulting in a coating of $10 \mathrm{~nm}$ after 30 s. The samples were examined visually using a FEI Quanta 3D FEG Dual Beam SEM (FEI Ltd, Hillsboro, USA) at $5 \mathrm{kV}$.

\subsection{Statistical Analysis}

Statistical analysis was performed using SPSS 19.0 (SPSS Inc., Chicago, USA). The surviving population of E. coli, Salmonella and L. monocytogenes and ozone concentration following ACP treatment were subjected to analysis of variance (ANOVA). Means were compared according to the method of Fisher's Least Significant Difference-LSD at the 0.05 level.

\section{Results}

Generally, indirect ACP treatment with subsequent $24 \mathrm{~h}$ of storage effectively reduced the numbers of microorganisms on either produce surface studied. On cherry tomatoes, treatments for $10 \mathrm{~s}, 60 \mathrm{~s}$, and $120 \mathrm{~s}$ reduced populations of Salmonella, E. coli and L. monocytogenes to undetectable levels, respectively. However, an extended treatment time of $300 \mathrm{~s}$ was necessary to reduce bacterial populations attached on the more complex surface of strawberries. 
199

200

201

202

203

204

205

206

207

208

209

210

211

212

213

214

215

216

217

218

219

220

221

222

223

\subsection{Inactivation of bacteria on cherry tomatoes}

The influence of ACP treatments on viability of E. coli, Salmonella and L. monocytogenes is represented in Figure 2. Tomato samples were inoculated with an average of $3.1 \pm 0.6 \log _{10}$ CFU/sample for E. coli, $6.3 \pm 0.6 \log _{10}$ CFU/sample for Salmonella and $6.7 \pm 0.6 \log _{10}$ CFU/sample for L. monocytogenes. After treatment for $10 \mathrm{~s}$ and above Salmonella populations on tomato were undetectable. Treatment for $45 \mathrm{~s}$ reduced populations of $E$. coli and L. monocytogenes by $2 \pm 1.2$ and $4.5 \pm 0.2 \log _{10}$ CFU/sample, respectively. Further increasing treatment time from $45 \mathrm{~s}$ to $60 \mathrm{~s}$ reduced populations of $L$. monocytogenes by 5.1 $\pm 0.5 \log _{10} \mathrm{CFU} / \mathrm{sample}$ and reduced populations of $E$. coli to undetectable levels. Populations of L. monocytogenes were reduced to levels below detection limits after extended treatment for $120 \mathrm{~s}$.

\subsection{Inactivation of bacteria on strawberries}

Reductions of E. coli, Salmonella and L. monocytogenes inoculated on strawberries are represented on Figure 3. The average initial attached population of E. coli, Salmonella and L. monocytogenes was $4.4 \pm 1.7,6.6 \pm 1.2$ and $7.3 \pm 0.3 \log _{10} \mathrm{CFU} /$ sample, respectively. After 60 s and $120 \mathrm{~s}$ of ACP treatment, populations of $E$. coli were reduced by $1.2 \pm 1.6$ and $1.6 \pm 0.1$ $\log _{10} \mathrm{CFU} /$ sample, respectively, with significantly different reductions of $3.5 \pm 0.7 \log _{10}$ CFU/sample achieved after treatment for $300 \mathrm{~s}(\mathrm{P} \leq 0.05)$. Similarly, populations of Salmonella were reduced by $1.7 \pm 0.1$ and $3.8 \pm 0.4 \log _{10}$ CFU/sample after ACP exposure for $120 \mathrm{~s}$ and $300 \mathrm{~s}$, respectively. No significant difference in antimicrobial efficacy of ACP treatments for either $120 \mathrm{~s}$ or $300 \mathrm{~s}$ against L. monocytogenes was observed where average reductions of approximately $4.2 \pm 0.5 \log _{10} \mathrm{CFU} / \mathrm{sample}$ were recorded. No changes were noticed in the levels of bacterial populations attached on the untreated control tomato or strawberries samples after storage for $24 \mathrm{~h}$.

\subsection{Inactivation of background microflora on produce}


224 The reductions of background microflora on cherry tomatoes and strawberries due to indirect

225 ACP treatments are represented on Figure 3.

226 An average of initial background microflora on cherry tomatoes was $5 \pm 0.1 \log _{10}$

227 CFU/sample (Fig. 4a). After $60 \mathrm{~s}$ of ACP treatment the aerobic mesophilic counts were 228 reduced by $3 \pm 0.7 \log _{10} \mathrm{CFU} / \mathrm{sample}$ while yeasts and moulds were reduced by $2.5 \pm 0.6 \log _{10}$

$229 \mathrm{CFU} / \mathrm{sample}$. Further increase in treatment time to $120 \mathrm{~s}$ resulted in reductions of yeasts and 230 moulds to undetectable levels while population of mesophilic bacteria was reduced of by 4.2 $231 \pm 0.8 \log _{10} \mathrm{CFU} /$ sample. Mesophilic bacteria were not detected when the treatment time was 232 increased to $300 \mathrm{~s}$. Untreated and stored for $24 \mathrm{~h}$ samples showed no changes in the growth 233 levels of background microflora on tomato samples.

234 Lower reduction levels of spoilage microorganisms by ACP treatment were observed in the case of strawberry samples (Fig. 4b). Significant decrease in mesophilic counts was observed after $60 \mathrm{~s}$ of ACP treatment, resulting in reductions by $1.6 \pm 0.9 \log _{10} \mathrm{CFU} /$ sample $(\mathrm{P} \leq 0.05)$ from the control $3.6 \pm 0.3 \log _{10} \mathrm{CFU} /$ sample. Populations of mesophilic bacteria did not decrease further when treatment time was extended from $60 \mathrm{~s}$ to either $120 \mathrm{~s}$ or $300 \mathrm{~s}$. Populations of yeasts and moulds initially present on strawberries were $5.5 \pm 0.1 \log _{10}$ CFU/sample. These levels decreased by $1.0 \pm 0.8 \log _{10} \mathrm{CFU} /$ sample after $120 \mathrm{~s}$ of ACP treatment. Extending the treatment time from $120 \mathrm{~s}$ to $300 \mathrm{~s}$ resulted in an additional $0.4 \pm 0.4$ $\log$ reduction in the population of yeasts and moulds. It should be noted that the levels of mesophilic bacteria of untreated control strawberry samples increased by $1.8 \pm 1.0 \log _{10}$ CFU/sample during $24 \mathrm{~h}$ storage, whereas populations of yeasts and moulds remained the same.

\subsection{Ozone generation}

247 Generation of ozone inside the sealed package containing either cherry tomatoes or strawberry samples as a function of ACP treatment time is represented in Figure 5. The ozone 
concentration inside the package containing cherry tomatoes increased gradually with increasing the treatment time. All ACP treatment times studied resulted in significant increase of ozone concentration $(\mathrm{P} \leq 0.05)$ with maximum concentration of $5600 \mathrm{ppm}$

252 achieved after $300 \mathrm{~s}$ of treatment. However, no significant difference in ozone concentration generated during the treatment of strawberry samples was observed. ACP treatment for $60 \mathrm{~s}$ resulted in an average of $2800 \mathrm{ppm}$, and further increasing treatment time from $60 \mathrm{~s}$ to 120 and 300 s resulted in an average of 3200 and 3500 ppm of ozone, respectively.

\subsection{Scanning Electron Microscopy (SEM)}

In order to examine if the complex substrate surface features had any effect on the bacterial adherence, and thus effect antimicrobial efficacy of ACP treatment, SEM analysis of untreated E. coli and L. monocytogenes inoculated on produce surface was conducted. Figure 6(a,b) represents the surface of strawberry and tomato, respectively, inoculated with $L$. monocytogenes where strong bacterial attachment in the form of clusters was noticed. On the contrary, only a small amount of individually attached bacterial cells of $E$. coli on the rough surface of strawberry was found (Fig. 6c).

\section{Discussion}

The indirect ACP treatment showed better inactivation efficacy against inoculated challenge bacteria and background microflora present on the surface of the two different products tested. Cherry tomatoes were selected as they have been associated with recent foodborne illness outbreaks and represent common raw food ingredients of commercial salads. Strawberries are also popular fruits and consumed raw. Moreover, these produce types present different surface decontamination challenges to the ACP system, i.e. tomato surface which is smooth, and the more complex surface of strawberry - uneven with numerous seeds. In general, higher inactivation rates due to $\mathrm{ACP}$ treatment were achieved for bacteria inoculated on smooth surface of tomatoes. Salmonella and E. coli were more rapidly 
inactivated on tomato than L. monocytogenes. Among the three bacteria studied, Salmonella was the most sensitive to $\mathrm{ACP}$, where $10 \mathrm{~s}$ of treatment time reduced bacterial population to undetectable levels. For tomato, increasing treatment time enhanced the inactivation efficacy of ACP in the case of E. coli and L. monocytogenes. Increasing treatment time from $45 \mathrm{~s}$ to $60 \mathrm{~s}$ inactivated $E$. coli populations present on tomatoes, whereas inactivation to undetectable levels of L. monocytogenes was obtained only after an extended treatment time of $120 \mathrm{~s}$. It is reported that Gram positive bacteria are more resistant to ACP treatments than Gram negative (Montie et al. 2000; Lee et al. 2006; Ermolaeva et al. 2011; Frohling et al. 2012a), which was also clearly demonstrated in the current study. Salmonella and E. coli are Gram negative bacteria with a thinner outer membrane compared to the Gram positive L. monocytogenes. The thicker membrane of the Gram positive bacteria may present a barrier to the diffusion of plasma reactive species through the bacterial cell wall, thus impacting antimicrobial efficacy.

On the contrary, Fan et al. (2012) revealed greater sensitivity of Gram positive L. innocua than Gram negative Salmonella and E. coli inoculated on tomato surface. Interestingly, other comparative studies reported similar susceptibility between Gram positive and Gram negative bacteria to ACP with respect to inactivation (Kostov et al. 2010; Olmez and Temur 2010; Klampfl et al. 2012). Clearly, the target cell characteristics are important factors for inactivation efficacy, but no clear trend is apparent and complex interactions with the system, process, surface or medium may also impact on efficacy in combination with cell type.

In this study we observed that the difference in the initial levels of the attached bacterial populations complicates the comparison of the bacterial sensitivity to the ACP treatments based on bacterial cell membrane characteristics. It is widely accepted that high initial bacterial concentration may affect inactivation efficacy of plasma treatment. The study conducted by Fernandez et al. (2012) clearly demonstrated that increasing the concentration of $S$. Typhimurium from 5 to $8 \log _{10}$ CFU/filter reduced the inactivation efficiency of ACP, 
suggesting that the initial concentration of microorganisms present on foods plays an important role in the efficacy of plasma treatment. In the present work, the lower initial populations of $E$. coli attached on tomatoes surface did not necessarily contribute to the increased ACP bactericidal characteristics. Within $45 \mathrm{~s}$ of treatment populations of $E$. coli were reduced by $2 \log$ from the initial $3.1 \log _{10} \mathrm{CFU} / \mathrm{sample}$, whereas this treatment time resulted in the reductions of $L$. monocytogenes populations by $4.5 \log$ from the initial 6.7 $\log _{10} \mathrm{CFU} / \mathrm{sample}$, and only $10 \mathrm{~s}$ was required to reduce Salmonella by $6.3 \log _{10} \mathrm{CFU} / \mathrm{sample}$.

This indicates the importance of the mechanisms and strengths of bacterial attachment with respect to a decontamination procedure. It has also been demonstrated that the resistance to ACP may also vary between bacteria species. Despite the higher inoculation levels on tomato surface, Salmonella appeared to be more sensitive than E. coli. Similar results were achieved in the research conducted by Niemira and Sites (2008) where Salmonella Stanley was more sensitive to ACP than E. coli inoculated on both agar and apple surfaces.

The influence of the produce type on the overall antimicrobial efficacy of ACP was observed when results are compared with the strawberry decontamination study. Treatment for $120 \mathrm{~s}$ significantly reduced L. monocytogenes inoculated on strawberries. Increasing treatment time to $300 \mathrm{~s}$ did not yield any further reductions of bacteria. However, after $300 \mathrm{~s}$ of treatment, a proportional reduction of E. coli and Salmonella was achieved. Strawberry surface is more porous than the surface of tomato. Irregularities of the fruit surface may provide many niche areas for bacteria, providing physiological barrier or protection against ACP treatments. This factor probably contributed to the reduced ACP bactericidal effect on Gram negative bacteria on strawberries by comparison with tomatoes.

The influence of the complexity of the produce surface structure on inactivation efficacy of ACP was observed when treatments were evaluated for the reduction of background microflora naturally present on the produce. The causative agents of microbial spoilage in 
fruits and vegetables can be bacteria (Erwinia spp., Enterobacter spp., Propionibacterium chlohexanicum, Pseudomonas spp., and lactic acid bacteria) as well as moulds and yeasts (Penicillium spp., Aspergillus spp., Alternaria spp., and Saccharomyces spp., Cryptococcus spp., Rhodotorula spp.) (Raybaudi-Massilia et al. 2009). In recent study conducted by Jensen et al. (2013), 34 different species from 23 different genera for bacteria and 22 different species from 9 different genera for yeasts were identified in strawberry samples. Despite this potential diversity of indigenous microflora, an ACP treatment time of $120 \mathrm{~s}$ significantly reduced the numbers on smooth surface of tomatoes in our study. However, again ACP was not very effective for the reduction of background microflora on more complex surface of strawberries, although tomato and strawberries tend to share similar bacterial communities (Leff and Fierer 2013).

Current information available for characterisation of ACP suggests that plasma is a source of heat, UV radiation, charged particles and reactive oxygen and nitrogen based species (ROS and RNS, respectively) with a main role given to the ROS as prime plasma disinfectants (Laroussi and Leipold 2004; Laroussi 2009). In this study, it was demonstrated that increasing the treatment time resulted in increased antimicrobial efficacy of ACP against bacteria inoculated on produce. Moreover, the inoculated samples were indirectly exposed to plasma, i.e., at some distance to the plasma discharge $(\sim 160 \mathrm{~mm}$ from the centre of the plasma discharge). In case of indirect treatment the charged particles and the short-lived species would not be expected to play a role due to their potential to recombine before reaching the sample (Laroussi 2009). Therefore, ozone was expected to be one of the key factors contributing to antimicrobial efficacy of ACP treatments. It has been demonstrated earlier that considerable reductions of bacteria by indirect ACP occurred within seconds when extended post treatment storage was applied, suggesting diffusion of the reactive species into liquids during post-treatment storage, thereby affecting microbial cells (Ziuzina 
et al. 2013). Extended $24 \mathrm{~h}$ post treatment storage time was also employed in the current

study. It is likely that $24 \mathrm{~h}$ post treatment storage time facilitated ACP action on the bacterial

cells by retaining generated reactive species within closed container, thus, promoting diffusion of the species inside the product tissue.

In the current work, as the treatment time increased, a significant increase in the ozone generated by plasma inside the package containing produce was noted $(\mathrm{P} \leq 0.05)$. However, it was also observed that the produce type influenced the concentration of ozone, where lower ozone levels were recorded for strawberry samples. Strawberries surface exhibit numerous pores, likely making the surface contact area larger than the area of tomato surface. This surface area differential may contribute to the increased dissolution rate of ozone generated inside the strawberry package, with subsequent reduced antimicrobial efficacy of ACP with regard to the all bacteria tested.

Considering the lower ozone concentrations and the consequent lower reductions of the challenge bacteria and background microflora on strawberries, it is likely that protection by more complex produce structures could be a critical parameter determining plasma treatment efficacy. Similarly, Fernandez et al. (2013) demonstrated that antimicrobial efficacy of plasma was influenced by produce surface features with higher bacterial reduction levels achieved on microbial filters than on more complex biotic surfaces.

As mentioned earlier, in this study, variations between initial populations of bacteria were apparent, with Salmonella and L. monocytogenes more readily attaching on the surface of either produce than E. coli. Regardless of the different surface features of the produce studied, SEM images confirmed the larger populations of L. monocytogenes adherent cells in addition to clusters of cells present. Despite the irregular nature of strawberry surface, which would probably facilitate bacterial attachment, E. coli populations visualised by SEM on the fruit surface were still less dense by comparison with $L$. monocytogenes images. A possible 
explanation for the lower levels of attached E. coli is the presence and interaction with naturally existing indigenous epiphytic bacteria. Depending on the types of epiphyte present the survival of pathogens can be either enhanced or inhibited (Erickson 2012). For example, Cooley et al. (2006) demonstrated that one epiphyte Enterobacter asburiae isolated from lettuce inhibited colonisation of E. coli, whereas another epiphyte Wausteria paucula had the opposite effect; enhancing E. coli survival.

Other factors that may affect microbial attachment to fresh produce are the different morphology and chemistry of the produce as different fruits and vegetables offer different microniches for the attachment, penetration and proliferation of bacteria (Keeratipibul et al. 2011). Motility of microorganisms facilitates pathogen entry into wounds, stomata and other existing fruit surface openings (Deering et al. 2012). We observed in SEM images that bacterial cells were likely adhered inside the natural crevices of produce surface or close to these regions. Naturally existing crack and pits on the surface of produce provide bacteria opportunity to internalise. Internalisation through the naturally existing opening is widely described in literature and considered as one of the major route of pathogens entry to plant tissue (Deering et al. 2012). Incidences of internalisation dependent upon concentration of bacteria, their location on the plant, age, integrity and stages of plant development, as well as indigenous agonistic/antagonistic bacteria present on plant have been reported (Erickson 2012; Shi et al. 2009). This study indicated that the decontaminating effect of ACP is a function of produce type and the contaminating pathogen. The produce surface has an influence on pathogen attachment, with the potential for internalisation particularly associated with minimally processed fresh produce. Therefore the depth to which the plasma generated chemical species are able to diffuse through a tissue in order to affect internalised cells or those within a biofilm requires further investigation to elucidate how that diffusion capability of ACP can be effectively harnessed. Overall, the results of this study indicated 
that bacterial attachment and increased survivability on more complex surfaces following

ACP treatments should be considered as very important factors influencing treatment design.

401

\section{Conclusion}

402

In summary, the high voltage indirect ACP treatment was highly efficient for decontamination of fresh produce inside a sealed package. Short treatment times of $10,60 \mathrm{~s}$ and $120 \mathrm{~s}$ resulted in reductions to undetectable levels of Salmonella, E. coli and L. monocytogenes, respectively on cherry tomatoes. However, treatment times of up to $300 \mathrm{~s}$ were required to attain substantial reductions on strawberry surfaces. Similarly, yeasts/moulds and mesophiles on tomato surface were not detected after 120 to $300 \mathrm{~s}$, respectively. Thus, it can be concluded that ACP treatment with $24 \mathrm{~h}$ post treatment storage can eliminate microorganisms on fresh produce surfaces inside a sealed package. In order to achieve optimum decontamination efficiency by ACP, factors including type of produce, their inherent surface characteristics, bacterial type, the strength and the nature of their attachment as well as the diffusion capacity of the plasma species, to holistically address the food safety issues associated with fresh produce, should be considered.

Acknowledgements

The research leading to these results has received funding from the European Community's

Seventh Framework Program (FP7/2207-2013) under grant agreement number 285820.

\section{References:} quality of fresh, minimally-processed fruit and vegetables, and sprouts from retail establishments. International Journal of Food Microbiology, 123, 121-129. G. (2010). Fresh fruit and vegetables as vehicles for the transmission of human pathogens. Environmental Microbiology, 12, 2385-2397. 
Centers for Disease Control and Prevention (CDC). (2012). Multistate Outbreak of Listeriosis Linked to Whole Cantaloupes from Jensen Farms, Colorado. Available at http://www.cdc.gov/listeria/outbreaks/cantaloupes-jensen-farms/082712/index.html [Accessed on 26 March 2013].

Cevallos-Cevallos, J.M., Gu, G., Danyluk, M.D., Dufault, N.S., Ariena van Bruggen, H.C. (2012). Salmonella can reach tomato fruits on plants exposed to aerosols formed by rain. International Journal of Food Microbiology, 158, 140-146.

Cooley, M.B, Chao, D. and Mandrell, R.E. (2006). Escherichia coli O157:H7 survival and growth on lettuce is altered by the presence of epiphytic bacteria. Journal of food protection, 69, 2329-2335.

Das, E., Gürakan, G.C. and Bayindirli, A. (2006). Effect of controlled atmosphere storage, modified atmosphere packaging and gaseous ozone treatment on the survival of Salmonella Enteritidis on cherry tomatoes. Food Microbiology, 23, 430 - 8.

Deering, A.J., Mauer, L.J. and Pruitt, R.E. (2012). Internalization of E. coli O157:H7 and Salmonella spp. in plants: A review. Food Research International, 45, 567-575.

Erickson, M. C. (2012). Microbial ecology. Produce contamination. In Decontamination of Fresh and Minimally Processed Produce ed. Gomez-Lopez, V. M. pp. 3-29. USA: Wiley-Blackwell Publishing.

Ermolaeva, S.A., Varfolomeev, A.F., Chernukha, M. Yu., Yurov, D.S., Vasiliev, M.M., Kaminskaya, A.A., Moisenovich, M.M., Romanova, J.M., Murashev, A.N., Selezneva, I.I., Shimizu, T., Sysolyatina, E.V., Shaginyan, I.A., Petrov, O.F., Mayevsky, E.I., Fortov, V.E., Morfill, G.E., Naroditsky, B.S. and Gintsburg, A.L. (2011). Bactericidal effects of non-thermal argon plasma in vitro, in biofilms and in the animal model of infected wounds. Journal of Medical Microbiology, 60, 75-83.

Fan, X., Sokorai, K.J., Engemann, J., Gurtler, J.B., Liu, Y. (2012). Inactivation of Listeria innocua, Salmonella Typhimurium, and Escherichia coli O157:H7 on surface and stem scar areas of tomatoes using in-package ozonation. Journal of Food Protection, 75, 16118. 
Fernández, A., Noriega, E., and Thompson, A. (2013). Inactivation of Salmonella enterica serovar Typhimurium on fresh produce by cold atmospheric gas plasma technology. Food Microbiology, 33, 24 - 9.

Fernandez, A., Shearer, N., Wilson, D. R. and Thompson, A. (2012) Effect of microbial loading on the efficiency of cold atmospheric gas plasma inactivation of Salmonella enterica serovar Typhimurium. International Journal of Food Microbiology 152, 175 180.

Flessa, S., Lusk, D.M., Harris, L.J. (2005). Survival of Listeria monocytogenes on fresh and frozen strawberries. International Journal of Food Microbiology, 101, 255- 262.

Frohling, A., Baier, M., Ehlbeck, J., Knorr, D. and Schluter, O. (2012a) Atmospheric pressure plasma treatment of Listeria innocua and Escherichia coli at polysaccharide surfaces: inactivation kinetics and flow cytometric characterisation. Innovative food science and emerging technologies 13, 142 - 150.

Frohling, A., Durek, J., Schnabel, U., Ehlbeck, J., Bolling, J., Schlüter, O. (2012b). Indirect plasma treatment of fresh pork: Decontamination efficiency and effects on quality attributes. Innovative Food Science \& Emerging Technologies, 16, 381-390.

Gratao, P.L., Monteiro, C.C., Rossi, M.L., Martinelli, A.P., Peresc, L.E.P., Medici. L.O., Lea, P.J. and Azevedo, R.A. (2009). Differential ultrastructural changes in tomato hormonal mutants exposed to cadmium. Environmental and Experimental Botany, 67, $387-394$.

Issa-Zacharia, A., Kamitani, Y., Muhimbula, H., and Iwasaki, K. (2010). Antimicrobial effect of slightly acidic electrolyzed water for inactivation of Salmonella spp. and Escherichia coli on fresh strawberries (Fragaria L.). African Journal of Microbiology Research, 4, 2174-2180.

Jensen, B., Knudsen, I.M.B., Andersen, B., Nielsen, K.F., Thrane, U., Jensen, D.F., Larsen, J. (2013). Characterization of microbial communities and fungal metabolites on field grown strawberries from organic and conventional production. International Journal of Food Microbiology, 160, 313-322. 
Keeratipibul, S., Phewpan, A., and Lursinsap, C. (2011). Prediction of coliforms and Escherichia coli on tomato fruits and lettuce leaves after sanitizing by using Artificial Neural Networks. LWT - Food Science and Technology, 44, 130 - 138.

Klampfl, T.G., Isbary, G., Shimizu, T., Li, Y.F., Zimmermann, J.L., Stolz, W., Schlegelc, J., Morfilla, G.E. and Schmidt, H.U. (2012). Cold Atmospheric Air Plasma Sterilization against Spores and Other Microorganisms of Clinical Interest. Applied and Environmental Microbiology, 78(15):5077. doi: 10.1128/AEM.00583-12. Available at http://aem.asm.org/content/78/15/5077.full [Accessed on 17 April 2013].

Klockow, P.A., and Keener, K.M. (2009). Safety and quality assessment of packaged spinach treated with a novel ozone-generation system. LWT - Food Science and Technology, 42, 1047-1053.

Kostov, K.G., Rocha, V., Koga-Ito, C.Y., Matos, B.M., Algatti, M.A., Honda, R.Y., Kayama, M.E. and Mota, R.P. (2010). Bacterial sterilization by a dielectric barrier discharge (DBD) in air. Surface \& Coatings Technology, 204, 2954-2959.

Laroussi, M. 2009. Low-temperature plasmas for medicine? Plasma Science, IEEE Transactions on plasma science 37, 714-725.

Laroussi, M. and Leipold, F. (2004) Evaluation of the roles of reactive species, heat, and UV radiation in the inactivation of bacterial cells by air plasmas at atmospheric pressure. International Journal of Mass Spectrometry 233, 81 - 86

Lee, K., Paek, K., Ju, W.T, and Lee, Y. (2006). Sterilization of Bacteria, Yeast, and Bacterial Endospores by Atmospheric-Pressure Cold Plasma using Helium and Oxyge. The Journal of Microbiology, 44, 269-275

Leff, J.W and Fierer, N. (2013). Bacterial Communities Associated with the Surfaces of Fresh Fruits and Vegetables. PLoS ONE 8: e59310. doi:10.1371/journal.pone.0059310

Mahmoud, B.S.M. (2010). The effects of X-ray radiation on Escherichia coli O157:H7, Listeria monocytogenes, Salmonella enterica and Shigella flexneri inoculated on whole Roma tomatoes. Food Microbiology, 27, 1057-1063. 
507

508

509

510

511

512

513

514

515

516

517

518

519

520

521

522

523

524

525

526

527

528

529

530

531

532

533

534

535

Mahmoud, B.S.M., Bhagat, A.R., and Linton, R.H. (2007). Inactivation kinetics of inoculated Escherichia coli O157:H7, Listeria monocytogenes and Salmonella enterica on strawberries by chlorine dioxide gas. Food Microbiology, 24, 36-744.

Mattson, T.E., Johny, A.K., Amalaradjou, M.A.R., More, K., Schreiber, D.T., Patel, J., and Venkitanarayanan, K. (2011). Inactivation of Salmonella spp. on tomatoes by plant molecules. International Journal of Food Microbiology, 144, 464-468.

Montie, T. C., Kelly-Wintenberg, K. and Roth, J. R. (2000). An overview of research using the one atmosphere uniform glow discharge plasma (OAUGDP) for sterilisation of surfaces and materials. IEEE Transactions on plasma science 28,1

Niemira, B.A. (2012). Cold Plasma Decontamination of Foods. Annual Review of Food Science and Technology, 3, 125-142.

Niemira, B.A. (2012). Cold plasma reduction of Salmonella and Escherichia coli O157:H7 on almonds using ambient pressure gases. Journal of Food Science, 77, 171175.

Niemira, B.A. and Sites, J. (2008). Cold plasma inactivates Salmonella Stanley and Escherichia coli O157:H7 inoculated on golden delicious apples. Journal of Food Protection. 71, 1357-65.

Noriega, E., Shama, G., Laca, A., Díaz, M., Kong, M.G. (2011). Cold atmospheric gas plasma disinfection of chicken meat and chicken skin contaminated with Listeria innocua. Food Microbiology, 7, 1293-1300.

Olaimat, A.N. and Holley R.A. (2012). Factors influencing the microbial safety of fresh produce: A review. Food Microbiology 32, 1 - 19.

Olmez H. and Temur S.D. (2010). Effects of different sanitizing treatments on biofilms and attachment of Escherichia coli and Listeria monocytogenes on green leaf lettuce. LWT - Food Science and Technology 43, 964-970.

Rangel, J. M., Sparling, P. H., Crowe, C., Griffin, P. M. and Swerdlow, D. L. (2005). Epidemiology of Escherichia coli O157:H7 Outbreaks, United States, 1982-2002. Emerging infectious diseases, 11, 603-609.doi: 10.3201/eid1104.040739 Available at http://www.ncbi.nlm.nih.gov/pmc/articles/PMC3320345/ [Accessed on 26 March 2013]. 
536

537

538

539

540

541

542

543

544

545

546

547

548

549

550

551

552

553

554

555

556

557

558

559

560

561

562

Raybaudi-Massilia, R.M., Mosqueda-Melgar, J., Soliva-Fortuny, R. and Martin-Belloso, O. (2009). Control of Pathogenic and Spoilage Microorganisms in Fresh-cut Fruits and Fruit Juices by Traditional and Alternative Natural Antimicrobials. Comprehensive reviews in food science and food safety, 8, 157 - 180.

Roberts, A. and Wiedmann, M. (2005). Host-pathogen interaction. In Understanding pathogen behaviour. Virulence, stress response and resistance ed. Griffiths, M. pp.98-114. UK: Woodhead Publishing Limited.

Rod, S. K., Hansen, F., Leipold, F. and Knochel, S. (2012) Cold atmospheric pressure plasma treatment of ready-to-eat meat: inactivation of Listeria innocua and changes in productquality. Food microbiology 30, 1-6

Shi, X., Wu, Z., Namvar, A., Kostrzynska, M., Dunfield, K. and Warriner, K. (2009). Microbial population profiles of the microflora associated with pre- and postharvest tomatoes contaminated with Salmonella Typhimurium or Salmonella Montevideo. Journal of Applied Microbiology, 107, 329-338

Wang, H., Zhou, B. and Feng, H. (2012). Surface characteristics of fresh produce and their impact on attachment and removal of human pathogens. Produce contamination. In Decontamination of Fresh and Minimally Processed Produce ed. Gomez-Lopez, V. M. pp. 43-55. USA: Wiley-Blackwell Publishing.

Warning, A. and Datta, A.K. (2013). Interdisciplinary engineering approaches to study how pathogenic bacteria interact with fresh produce. Journal of Food Engineering, 114, $426-448$.

Ziuzina, D., Patil, S., Cullen, P.J., Keener, K.M. and P. Bourke. (2013). Atmospheric cold plasma inactivation of Escherichia coli in liquid media inside a sealed package. Journal of applied microbiology, 114, 778-787. 
Figures:

565

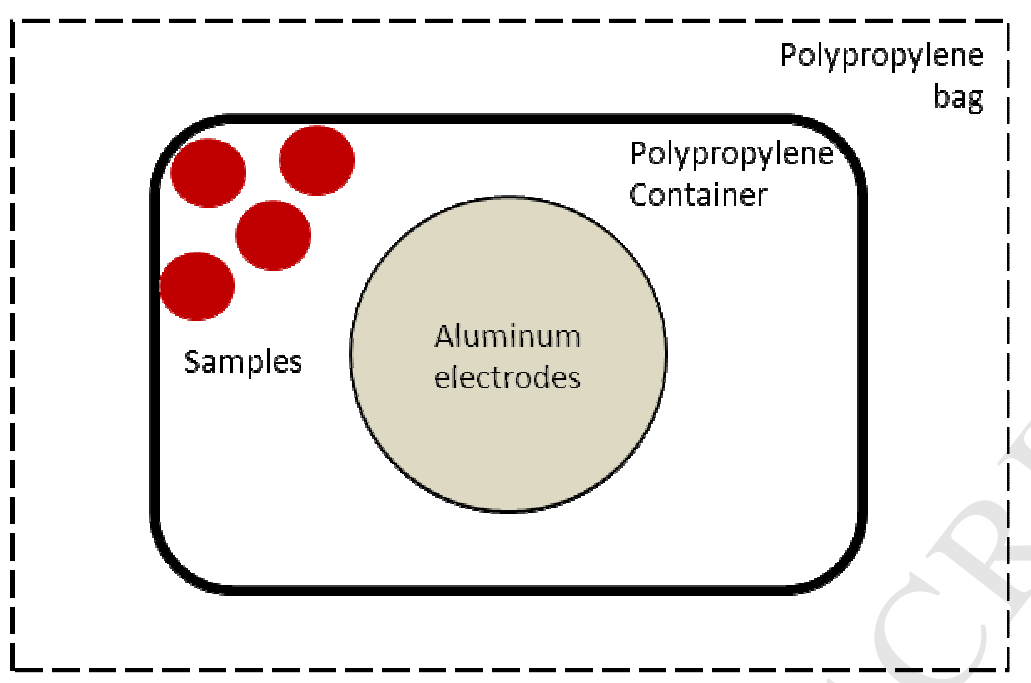

566 Fig.1: Schematic diagram of samples distributed within polypropylene container with respect 567 to the electrodes. 


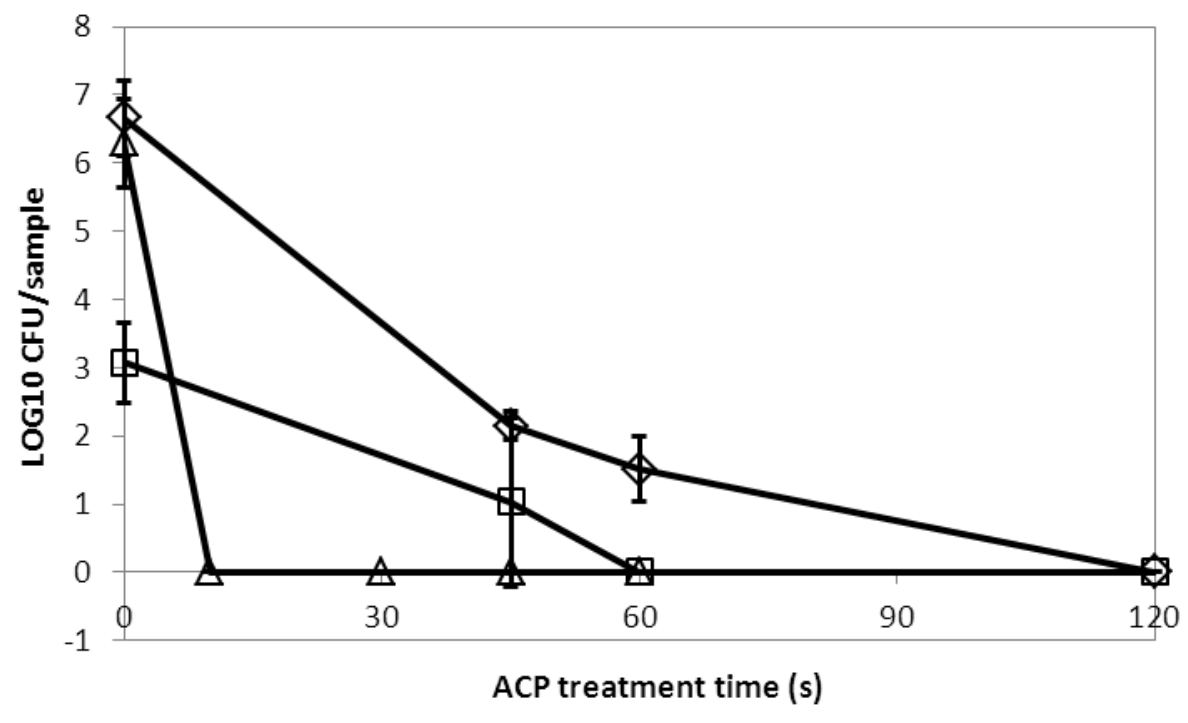

579

580 Fig.2: ACP inactivation efficacy against E. coli $(\square)$, Salmonella $(\Delta)$ and L. monocytogenes $(\diamond)$

581 inoculated on cherry tomatoes. Vertical bars represent standard deviation. Limit of detection

582 $1.0 \log _{10} \mathrm{CFU} / \mathrm{sample}$.

583

584

585

586

587

588

589

590

591

592

593

594

595

596 


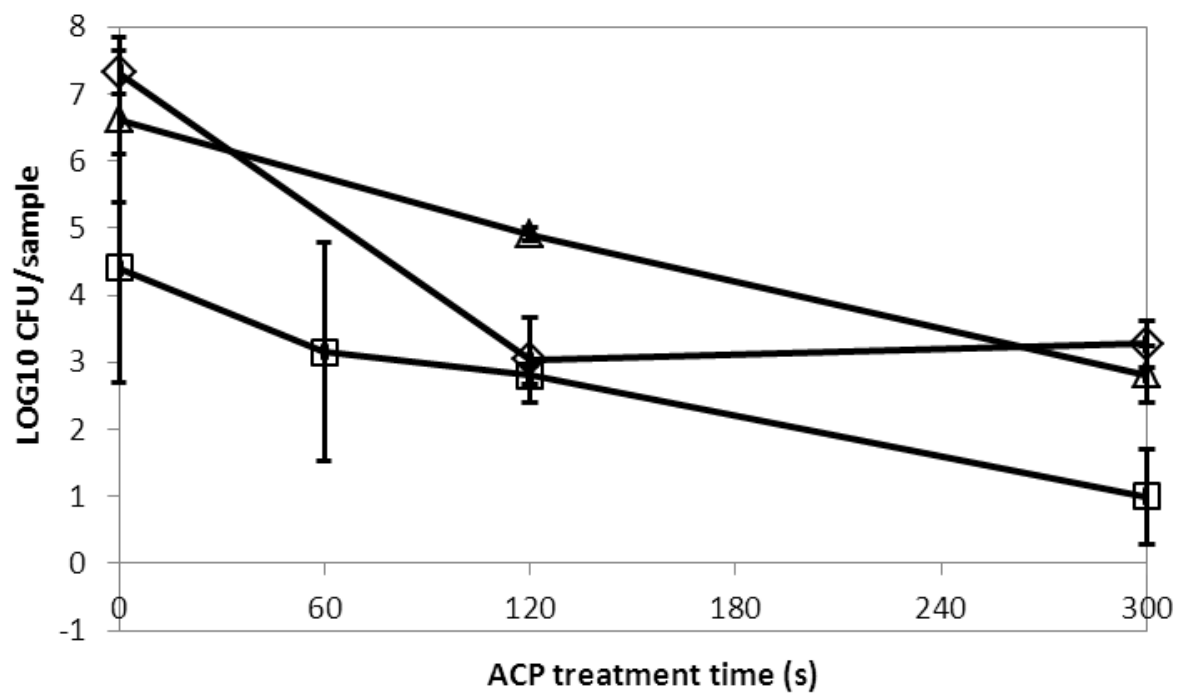

597

598 Fig.3: ACP inactivation efficacy against E. coli ( \, Salmonella $(\Delta)$ and L. monocytogenes $(\diamond)$

599 inoculated on strawberries. Vertical bars represent standard deviation. Limit of detection 1.0

$600 \log _{10} \mathrm{CFU} /$ sample.

601

602

603

604

605

606

607

608

609

610

611

612

613

614 


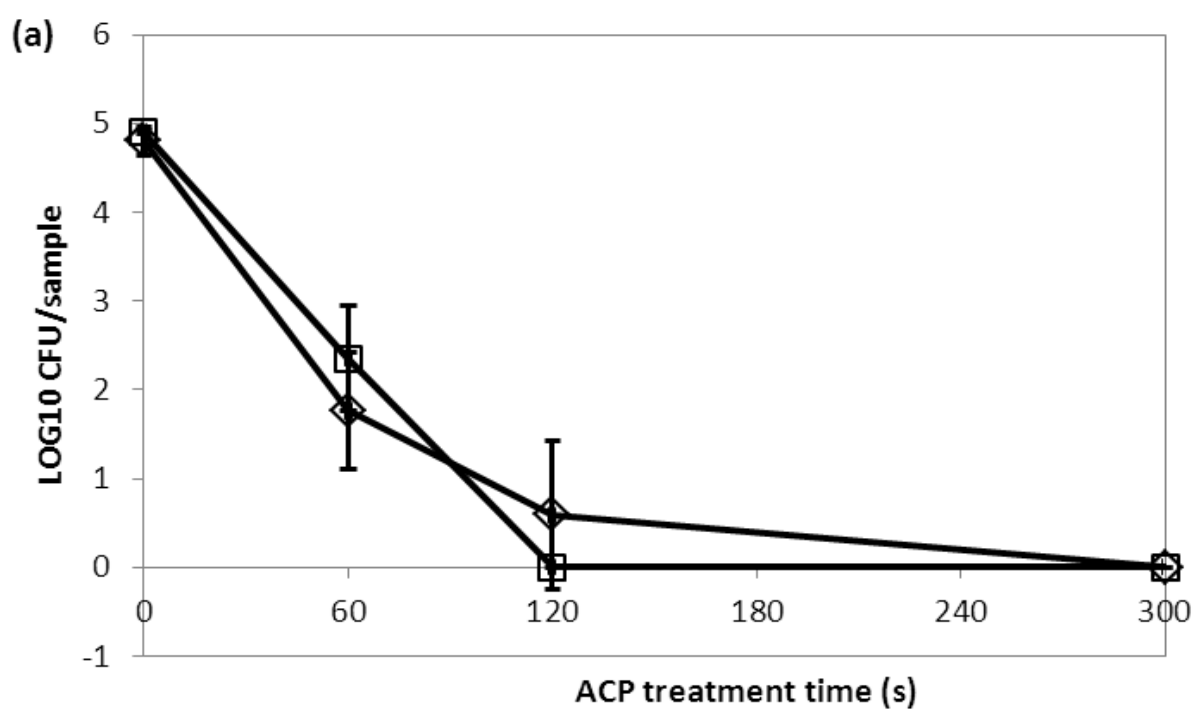

615

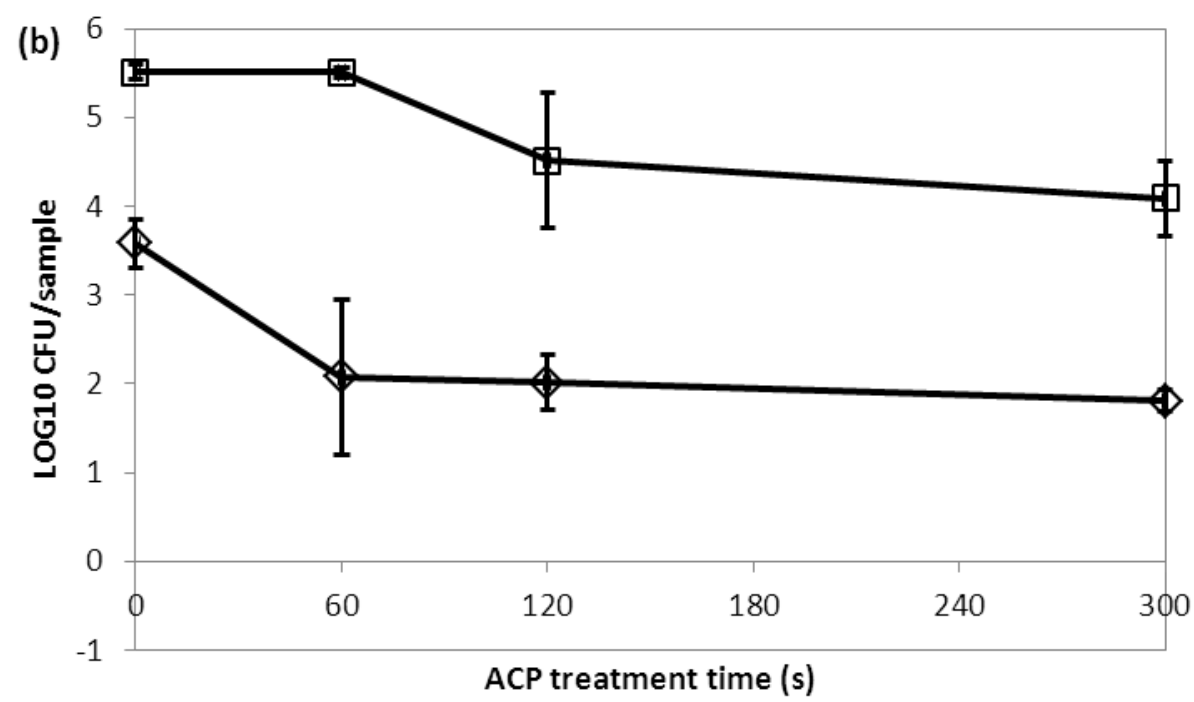

616

617 Fig.4: ACP inactivation efficacy against aerobic mesophilic bacteria $(\diamond)$ and yeasts and 618 moulds ( $\square$ ) on (a) cherry tomatoes and (b) strawberries. Vertical bars represent standard 619 deviation. Limit of detection $1.0 \log _{10}$ CFU/sample.

620

621

622

623

624 


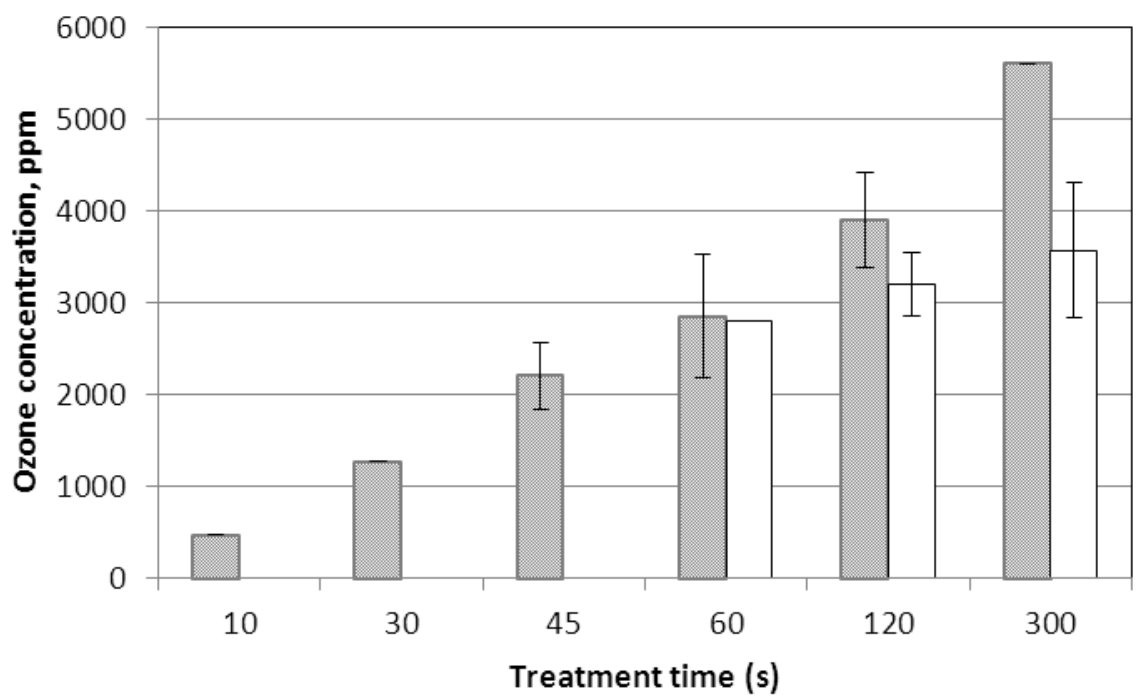

625

626 Fig.5: Generation of ozone inside a sealed package during ACP treatment of either inoculated 627 or uninoculated samples of cherry tomatoes (圆) and strawberries ( $\square$ ). Vertical bars represent 628 standard deviation.

629

630

631

632

633

634

635

636

637

638

639

640

641

642 
643

644

645

646

647

648

649

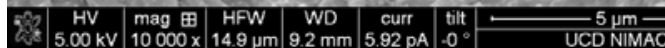

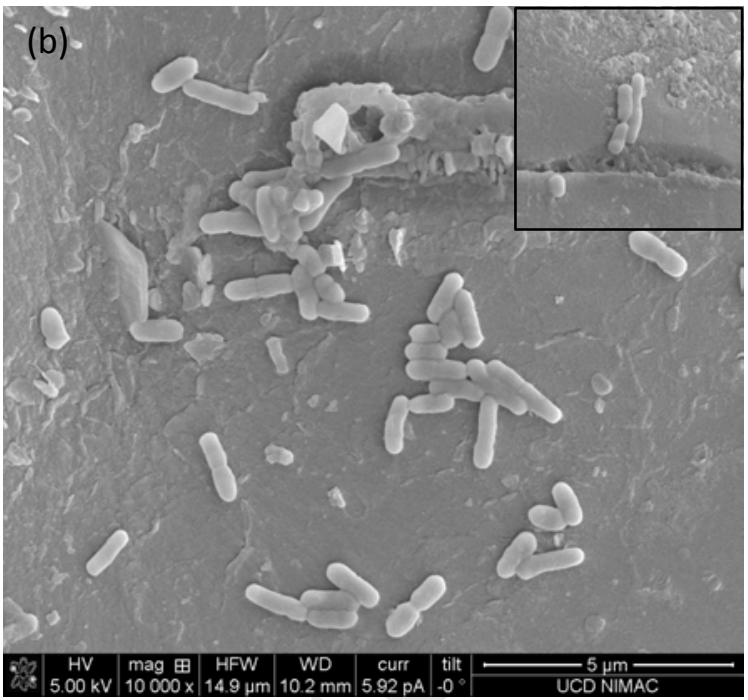

650

651

652

653

654

655

656

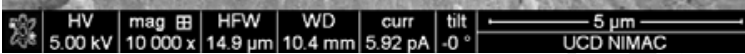

657

658 Fig.6: SEM images of untreated L. monocytogenes on (a) strawberries and (b) cherry tomatoes, and (c) E. coli inoculated on strawberry.

660

661

662

663 
YFMIC 2105 Food Microbiology

Atmospheric Cold Plasma inactivation of Escherichia coli, Salmonella enterica serovar

Typhimurium and Listeria monocytogenes inoculated on fresh produce

\section{Highlights}

- In this study antimicrobial efficacy of ACP against Escherichia coli, Salmonella enterica Typhimurium and Listeria monocytogenes inoculated on cherry tomatoes and strawberries was evaluated.

- A key advantage of this high voltage level treatment for in-package non-thermal decontamination approach is the possibility to eliminate post-processing contamination of the produce.

- This approach has potential to provide both increased microbiological food safety and extension of produce shelf life.

- Inactivation was however, dependent on fresh produce surface features and pathogen type. 